\title{
Application of Rationality in Strategic Decision Making and its Implementation at Branch level: A Case Study of Habib Bank Limited (HBL) Karachi
}

\author{
Ghulam Ali Mashori ${ }^{1}$, Aftab Ahmed ${ }^{2}$, Manzoor $\mathrm{Ali}^{3} \mathrm{Nadir} \mathrm{Ali}^{4}$ \\ ${ }^{1,3}$ Department of Management Sciences, BUITEMS, Quetta \\ ghulam.ali@buitms.edu.pk \\ manzoor.ali@buitms.edu.pk \\ ${ }^{2}$ Department of Computer Science, BUITEMS, Quetta \\ aftab.ahmed@buitms.edu.pk \\ ${ }^{4}$ Department of Petroleum \& Gas, BUITEMS, Quetta \\ nadir.khoso@buitms.edu.pk
}

\begin{abstract}
Purpose of this study is to analyze the rationality in decision making (specifically Strategic Decisions), implementation, and branch level managers' inputs in Strategic Decisions in Habib Bank Limited Karachi Pakistan. Researchers focus on to study the factors that can affect the rationality of strategic decision making. Although managers' have strong believe in rationality in decision making but evidences suggest that the managers' decisions are affected by improper identification of problem, due to work burden of managers, they generally make decision based on imperfect information, affected by bounded rationality, and escalation of commitment. Though, no clear evidences have been found about lobbying and satisficing as suggested by Herbert A. Simon's Administrative model for decision making. Organization's communication is affected by rigid formal hierarchy having many layers resultantly there is communication gap between top management and branch managers. Evidences also suggest that there is the problem of implementation of decisions as intended by top managers that may be the result of communication gap.
\end{abstract}

Key Words: Bounded rationality, Escalation of commitment, Rationality in decision making, Satisficing. 


\section{Introduction}

Organizations, in present era, are working in cut throat competition. Globalization approach has erased many trade barriers. Rapid innovation, advancement in new technology, reduction in product life cycle and huge investment increase the essence of taking right decisions particularly strategic decisions in order to save the company from huge losses, bad market image, to be out of business, and wastages of time and resources of the organization. It is utmost important for managers (particularly top managers) to be rational while taking decisions specifically strategic decisions and their implementation. Their decision should be based on sound information that can be generated through environmental scanning, proper identification of problem /opportunity, developing number of alternatives to the problem/opportunity, scientifically evaluating the costs and benefits of each alternative, selecting the most promising alternative and implementing the decision as intended.

Banking sector in Pakistan is very established sector, having a large number of banks (including public, private, national, conventional, Islamic and foreign banks). There is intensive competition among the banks that exerts a lot of pressure on managers. In this era of competition, it is imperative for managers to take right decisions specifically strategic decisions that set the long term direction of the company/ organization that require great amount of time and resources to implement.

Now-a-days, managers work in dynamic environment that requires keeping the close focus on environment changes in order to have proper alignment with environment with respect to opportunities and threats.

Maximum managerial time is consumed on meetings, supervisory activities, interactions with different stakeholders. They have less time to take very important decisions based on rational thinking. According to Herbert A. Simon, managers do not always take decisions based on rationality and logic. He argues, "managers have i) incomplete and imperfect information ii) are constrained by bounded rationality, and iii) tend to satisfice when making decision"(Griffin, 2006). Managers' rational decisions are also affected by intuition, escalation of commitment, coalition and risk propensity (Griffin, 2006).

Making the right decision is not only a sole criterion for organizational success but also implementation of decision is very crucial. Proper implementation needs to cultivate appropriate organizational culture that supports the new direction of the organization, making required resources available, strong implementation and control mechanism, strong communication and coordination among the managerial levels. It is also observed that sometime top management neither gets input from lower managerial levels for decisions making nor communicate the 
decisions clearly to the levels where decisions will be implemented. Consequently, middle and lower manager might have lack of commitment and disagreement for the decisions that have been made solely at the top. At whatever extent decisions are right but if they are not implemented properly then results of the decisions will not be as intended.

\subsection{Problem Statement}

Purpose of this study is to analyze the rationality in decision making (specifically Strategic Decisions) and implementation of decisions at different levels in Habib Bank Limited (HBL) Pakistan. This study is mainly focused on to identify the extent to which decisions are made on the basis of rational thinking as described in classical decision making model rather than the tendency of decision making based on imperfect information, affected by bounded rationality and satisficing. In order to make rational decisions it is very important to get proper inputs that are required for decision making. Not only decision making is important but also implementation at different levels as intended and involvement of those who carry on the decisions is very important so that researcher would try to find the answer of them.

\subsection{Research Objectives}

The objectives of this study are;

- To study the behavior and attitude of managers toward taking important decisions (strategic decisions) with respect to rational thinking.

- To identify and analyze the conscious efforts (if any) of managers to cultivate the environment conducive to the decisions to be implemented.

- To study the extent to which managers of different levels have close coordination and clear communication with respect to decision making and implementation.

- To evaluate the participation of branch level managers in important decisions.

\subsection{Benefits of the Study}

This research will enable managers of different organizations in general and managers of HBL in particular to concentrate on decision making pattern of organization (Strategic decisions), evaluating and making environment of organization conducive before implementing the decisions and reviewing the control mechanism of organization. Attention of managers on these dimensions will be crucial for long run survival of the organization.

\subsection{Geographic Scope}

Due to time and cost constraints, this study covers only HBL Head Office, and branches located in District Malir Karachi (including Area Branch located in Jinnah Terminal headed by Area Manager). Area Manager of this area supervises the eleven (11) branches. Nine branches are in District Malir and two branches in District East. 


\section{Research Methodology}

This research is descriptive and qualitative in nature. Both, primary and secondary data collection sources were used. Primary data was collected through two separate questionnaires. One questionnaire was administered on the perspective of top managers regarding the strategic decision making and another was intended to comprehend the context of branch level managers in relation to their input for strategic decision making, implementation and participation. Data was collected from Top Managers in Head Office and Senior Managers working in HBL branches (including consumer, commercial and corporate) mainly located in District Malir Karachi. Researcher had also conducted structured interviews with ten (two managers from top and eight branch level managers) managers in order to get inside about the subject. The secondary data was collected through books, research journals, websites and other published sources. Data is collected from Top Managers and Branch level Managers as well. The total population is 44 (22 top managers and 22 branch level managers). Because of limitation of proper access, time and cost, convenient sampling method was used due to nonavailability of respondents, access of branches and amount of time that is consumed in data collection. Nine questionnaires were distributed among the top managers and sixteen questionnaires were distributed among the branch level managers. Four out of nine questionnaires were returned back from top and thirteen out of sixteen questionnaires were returned back from branch level managers hence response rate remained $18.18 \%$ ( Top Managers) and $49 \%$ from Branch level Managers (Branch Managers and Operation Managers).

\section{Literature Review}

The decision making is the act of selecting one decision option from among a set of alternatives (Griffin, 2006; Courtland Bovee et al, 2000) and decision making process is recognizing and defining the nature of a decision situation, identifying alternatives, evaluating alternatives, choosing the best alternative and putting it into practice"(Griffin, 2006). The classical decision model is a perspective approach that tells managers how they should make decisions; it rests on a assumptions that while making the decisions managers are logical and rational and they take those decisions that are in the best interest of organization (Griffin, 2006; Kathryn M. et al, 19998).

The classical model of decision making views decision making process on assumptions that (1) decision makers have perfect-complete- information about the decision situation and possible alternatives, (2) they can effectively eliminate uncertainty to achieve a decision condition of certainty and (3) they evaluate all aspects of the decision situation logically and rationally(Griffin, 2006; Courtland Bovee et al, 2000). In actual practice these conditions rarely, if ever, exist. Herbert A. Simon was one of the first people to recognize that decisions are not always made on the basis of rationality and logic; his Administrative Model describes that managers (1) have incomplete and imperfect information, (2) are constrained by 
bounded rationality, and (3) tend to satisfice when they make decisions (Griffin, 2006). There are certain other behavioral forces that can influence decisions. The coalition, intuition, and escalation of commitment are the factors that can affect rationality of managers' decisions (Griffin, 2006; Kathryn M. et al, 1998). A coalition is an informal alliance of individuals or groups formed to achieve a common goal in terms of preferred decision, Intuition is an innate belief of someone about something without any conscious consideration, and escalation of commitment is a decision maker's behavior to be committed with the decision even when that decision appears to be wrong (Griffin, 2006).

Strategic decisions are those decisions that provide long term direction for a firm. The implementation of these decisions requires substantial investment, having long term effect, and irreversible (Prasanna, 2008). The literature available related to this topic is on strategic management as defined "a comprehensive and ongoing management process aimed at formulating and implementing effective strategies; it is way of approaching business opportunities and challenges (Griffin, 2006). Strategic management process includes four activities (1) review and define organization mission, (2) set long range goals and objectives, (3) analyze and formulate strategies to reach objectives, and (4) implement strategies (Clifford F. Gray \& Erik W. Larson, 2006).

Rationality in decision making is important for all businesses generally and banking sectors particularly. The importance of rationality in decision making in the financial services industry is described as "managers in the financial services industries are perceived as being extremely "rational" decision makers. The training and use of rational tools, such as discounted cash flow, net present value and other capital budgeting techniques, are wide spread throughout this industry" (Bei $\mathrm{Hu} \&$ Jiajun Gu 2007). While making the decisions, managers must study firm's internal and external environment this also suggested in rational-normal model as "managers choose strategies based on their firm's internal and external environment. Specially, managers first evaluate their external environmental circumstances and then examine their firm's internal resources and/or competencies. Managers select optimal strategies, given environmental demands" (Bei $\mathrm{Hu} \&$ Jiajun Gu 2007). Procedural rationality in decision making is also important as described as, "the extent to which the decision process involves the collection of information relevant to the decision and the reliance upon analysis of this information in making the choice"(Bei Hu \& Jiajun Gu 2007). Now-a-days, in the information technology era, it is utmost important to use computer based information data base and supporting tools in decision making. Decision Support System (DSS) is one of them. "Decision support systems (DSS) are computer based information system designed to help decision makers solve problems in illstructured decision making area. Successful DSS application has addressed problems and decisions in broad range of managerial and policy environment. By definition, ill-structured decision making environment are those not well enough understood to permit complete analytical description. This implies the need to combine managerial experience and judgment with qualitative computer based 
approaches. Thus DSS are primarily symbolized as providing a set of opportunities directed toward improving the effectiveness and productivity of managers and professionals, strengthening the organization's competitive and survival ability, and rationalizing the decision making process within an organizational context. They aim at realizing the desire for accurate, timely, and relevant information to help individual managers in organizations deal with an increasingly turbulent economic environment and growing pressure of competition"(Luo Yong Tai et all, 2000). In addition to rationality in decision making, managers also influenced by their intuition while making the decision. Intuition is an ability based on learning from past experience (without conscious consideration), rather than an innate cognitive complexity or discretionary ability (Bei $\mathrm{Hu} \&$ Jiajun $\mathrm{Gu}$ 2007). Conflict at the top management also affects the quality of decision and performance of firm. "Research proves that procedural rationality, intuition will be positively related to strategic decision making effectiveness, and while TMT (Top Management Teams) conflicts have contrary effect. Furthermore, procedural rationality has greater effect on strategic decision making effectiveness than intuition. It also finds strategic decision making effectiveness will be positively related to performance improvement. So, corporate want to improve the performance, they must decrease TMT conflict and pay attention on the procedural rationality and leaders' intuition, specially pay attention on the procedural rationality"( Bei $\mathrm{Hu} \&$ Jiajun $\mathrm{Gu}$ 2007). It is also important to know the relationship between procedural rationality and political behavior in strategic decision making. "This can be clarified by distinguishing between process-and choice-oriented models of decision making. Process models describe what people do when making a decision, for example, negotiation or analysis. Choice models explain why a given alternative is selected, for example, it offers the best long-term prospects for the firm or for powerful departments. This is strong evidence that procedural rationality and political behavior are distinct, independent dimensions of decision processes"( James W. Dean, Jr. \& Mark P.Sharfman). 


\section{Data Analysis and Findings}

\subsection{Response from Top Managers}

Table:1 Aggregate Response Table in Percentage

\begin{tabular}{|c|c|c|c|c|c|c|}
\hline Question & $\begin{array}{c}\text { Strongly } \\
\text { Disagree }\end{array}$ & Disagree & Neutral & Agree & $\begin{array}{c}\text { Strongly } \\
\text { Agree }\end{array}$ & Total \\
\hline 1 & 0 & 0 & 0 & 25 & 75 & 100 \\
\hline 2 & 50 & 25 & 25 & 0 & 0 & 100 \\
\hline 3 & 0 & 75 & 25 & & 0 & 100 \\
\hline 4 & 0 & 25 & 0 & 75 & 0 & 100 \\
\hline 5 & 25 & 75 & 0 & 0 & 0 & 100 \\
\hline 6 & 0 & 100 & 0 & 0 & 0 & 100 \\
\hline 7 & 0 & 0 & 100 & 0 & 0 & 100 \\
\hline 8 & 0 & 0 & 75 & 25 & 0 & 100 \\
\hline 9 & 0 & 0 & 0 & 75 & 25 & 100 \\
\hline 10 & 0 & 100 & 0 & 0 & 0 & 100 \\
\hline 11 & 0 & 0 & 0 & 100 & 0 & 100 \\
\hline 12 & 0 & 0 & 0 & 100 & 0 & 100 \\
$\begin{array}{c}\text { Aggregate } \\
\text { in\% }\end{array}$ & $\mathbf{6 . 2 5}$ & $\mathbf{3 3 . 3 3}$ & $\mathbf{1 8 . 7 6}$ & $\mathbf{3 3 . 3 3}$ & $\mathbf{8 . 3 3}$ & $\mathbf{1 0 0}$ \\
& & & & & & \\
\hline
\end{tabular}

\subsubsection{Individual Question wise Analysis}

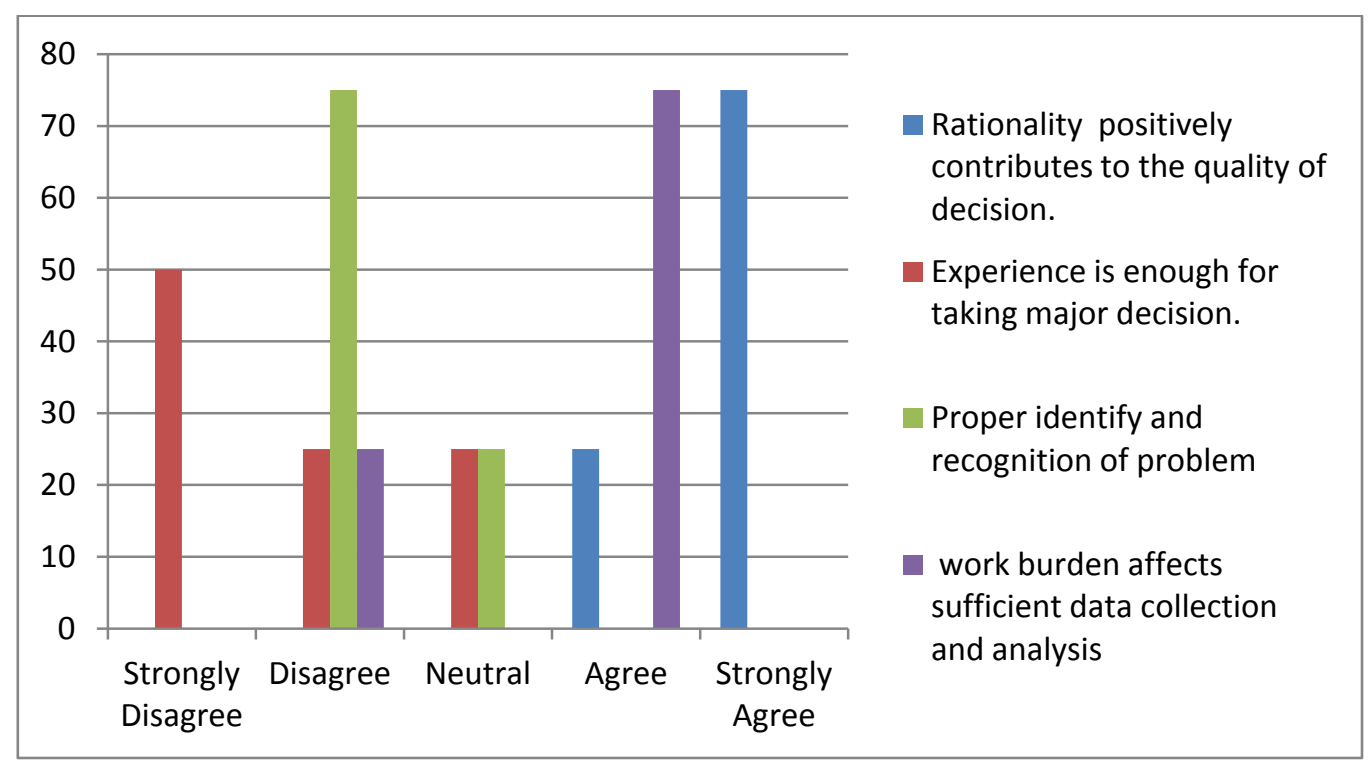


There is strong belief of top manages that rational analysis contributes positively to the quality of strategic decision (100\% respondents strongly agreed). Majority of top managers $(75 \%)$ have strong belief that experience is not enough criteria for making quality decisions $(50 \%$ of respondents strongly disagreed $25 \%$ disagreed that only experience is enough for making decisions. $25 \%$ of respondents remained neutral with the statement).Mostly top managers have opinion that managers do not identity the problem properly $(75 \%$ of respondents disagreed with the statement that the managers properly identify the problems and $25 \%$ remained neutral). Approximately $75 \%$ of respondents agreed that due to work burden of other activities it is difficult for managers to collect the sufficient amount of data that can be used as input for decision making. 25\% disagreed with the statement.

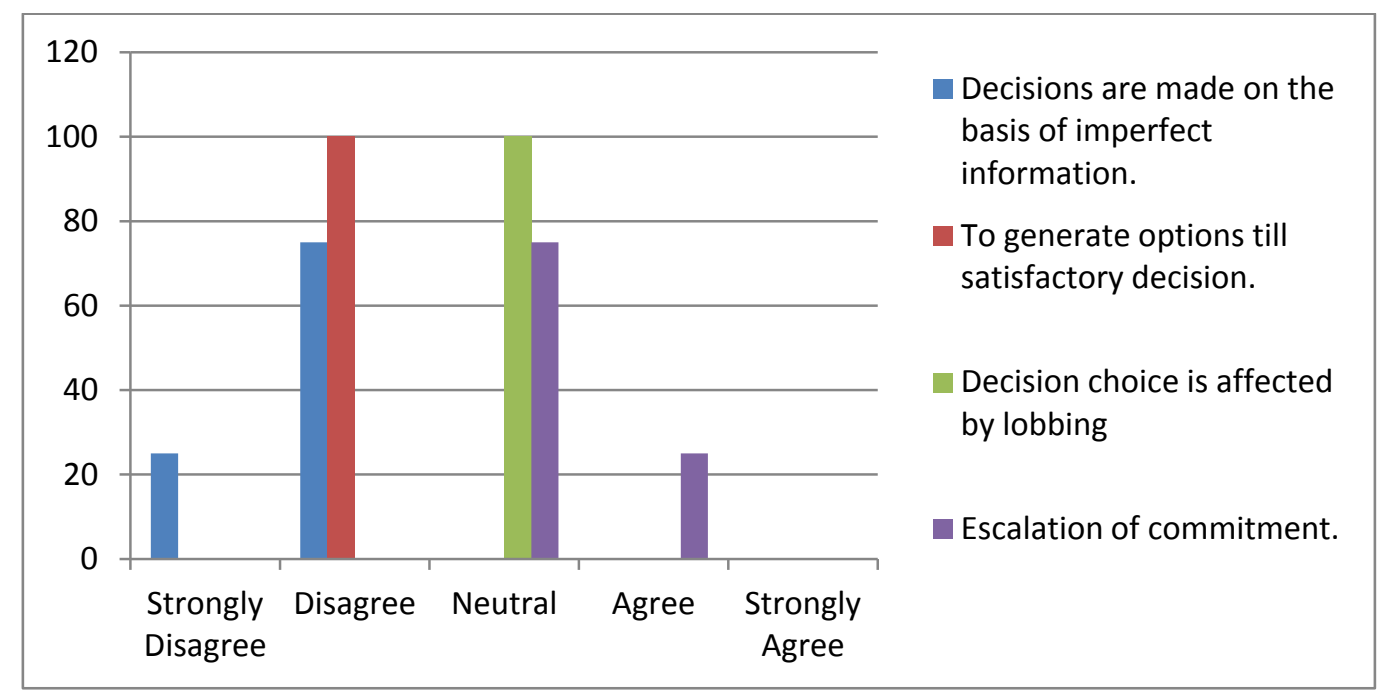

Fig 2

Almost majority disagreed with the statement that decisions are made based on imperfect information. All respondents $(100 \%)$ disagreed with the satisficing in decision making. All respondents $(100 \%)$ remained neutral with the statement that decision choice is affected by lobbing. Approximately $25 \%$ of respondents agreed with the escalation of commitment in decision making and $75 \%$ remained neutral. 


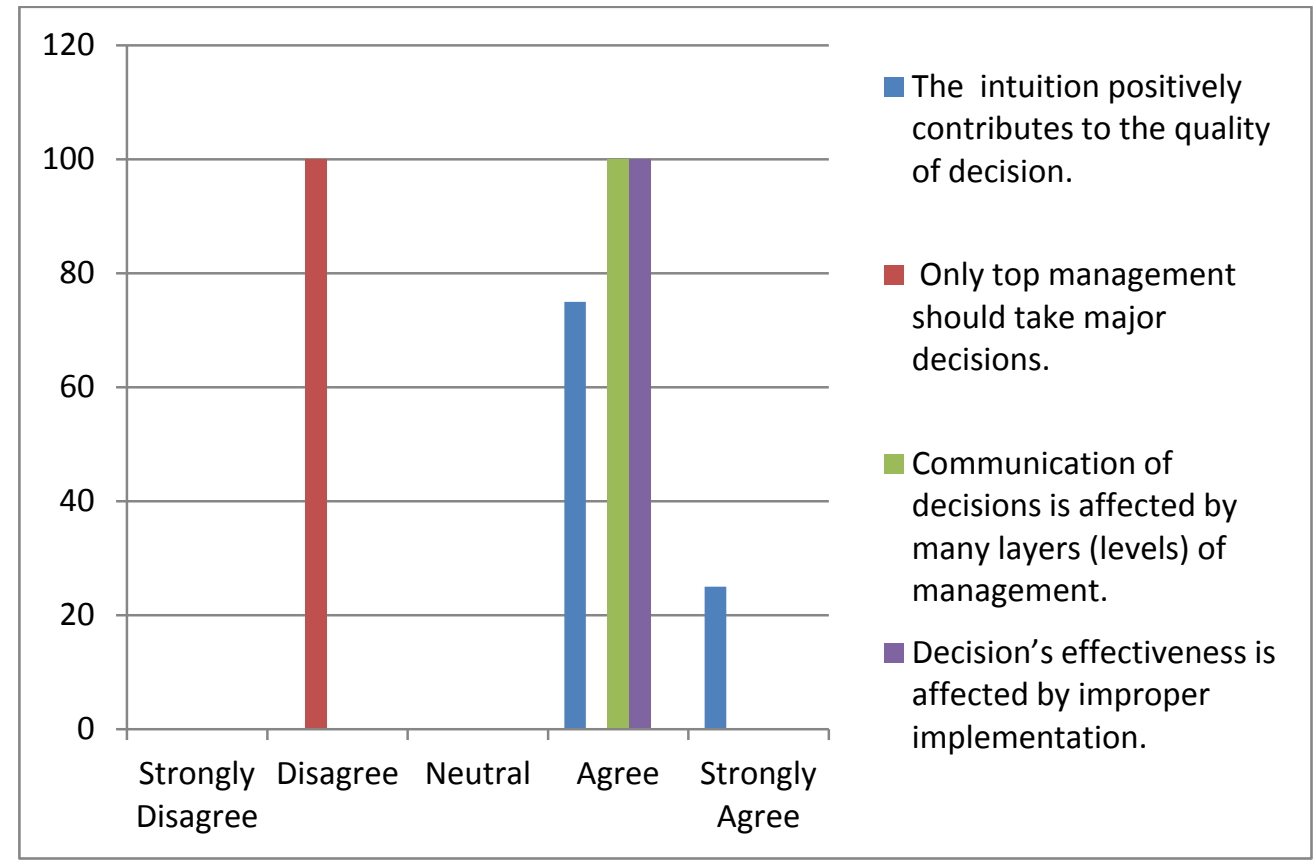

Fig 3

Managers have strong belief in intuition and positively correlated intuition with the quality of decision (75\% agreed and 25\% strongly agreed that intuition positively contributes to the quality of decision making). All respondents $(100 \%)$ disagreed with the statement that decisions are made without getting contribution from branch managers. Approximately $100 \%$ agreed that communication of decision is affected by many layers of hierarchy. All $(100 \%)$ agreed that effectiveness of decisions is affected by improper implementation. 


\subsection{Response from Branch level Managers.}

Table:2 Aggregate Response Table in Percentage

\begin{tabular}{|c|c|c|c|c|c|c|}
\hline Question & $\begin{array}{c}\text { Strongly } \\
\text { Disagree }\end{array}$ & Disagree & Neutral & Agree & $\begin{array}{c}\text { Strongly } \\
\text { Agree }\end{array}$ & Total \\
\hline 1 & 0 & 30 & 20 & 30 & 20 & 100 \\
\hline 2 & 0 & 30 & 0 & 40 & 30 & 100 \\
\hline 3 & 0 & 30 & 40 & 30 & 0 & 100 \\
\hline 4 & 0 & 30 & 10 & 50 & 10 & 100 \\
\hline 5 & 10 & 0 & 10 & 80 & 0 & 100 \\
\hline 6 & 0 & 10 & 0 & 60 & 30 & 100 \\
\hline 7 & 10 & 10 & 0 & 70 & 10 & 100 \\
\hline 8 & 0 & 10 & 20 & 40 & 30 & 100 \\
\hline 9 & 0 & 0 & 10 & 70 & 20 & 100 \\
\hline 10 & 0 & 10 & 0 & 80 & 10 & 100 \\
\hline 11 & 10 & 10 & 0 & 70 & 10 & 100 \\
\hline 12 & 0 & 50 & 0 & 50 & 0 & 100 \\
$\begin{array}{c}\text { Aggregate } \\
\text { in\% }\end{array}$ & $\mathbf{2 . 5}$ & $\mathbf{1 8 . 3 3}$ & $\mathbf{9 . 1 7}$ & $\mathbf{5 5 . 8 3}$ & $\mathbf{1 4 . 1 7}$ & $\mathbf{1 0 0}$ \\
\hline
\end{tabular}

\subsubsection{Individual Question wise Analysis:}

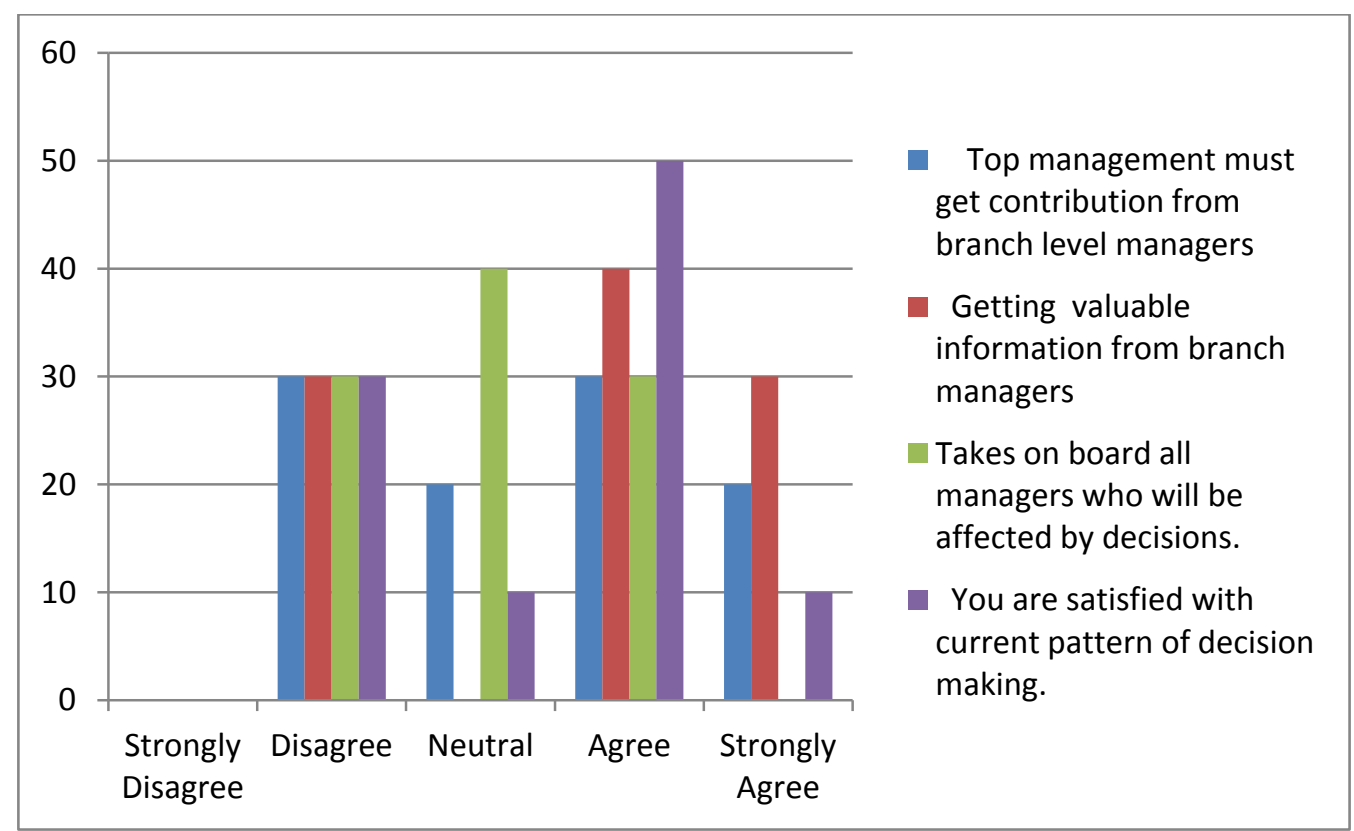


Approximately $30 \%$ of respondents strongly agreed and $20 \%$ agreed that top management must get input from branch level managers for taking major decisions 30\% disagreed and 20\% remained neutral with the statement. Majority of respondents (branch managers) have strong belief that they can provide valuable information that can be use as input for taking major decisions (40\% of respondents agreed, $30 \%$ strongly agreed with the statement that branch level managers can provide valuable information regarding major decisions and $30 \%$ disagreed with the statement). There is equal proportion of respondents approximately $30 \%$ of respondents agreed with the statement that top management takes on board all managers who are affected by the decision, $30 \%$ disagreed and $40 \%$ remained neutral with the statement. About $60 \%$ of respondents are satisfied with current pattern of decision making and $30 \%$ showed dissatisfaction (50\% of respondents agreed, $10 \%$ of respondents strongly agreed with current decision making pattern, 30\% disagreed and 10\% remained neutral).

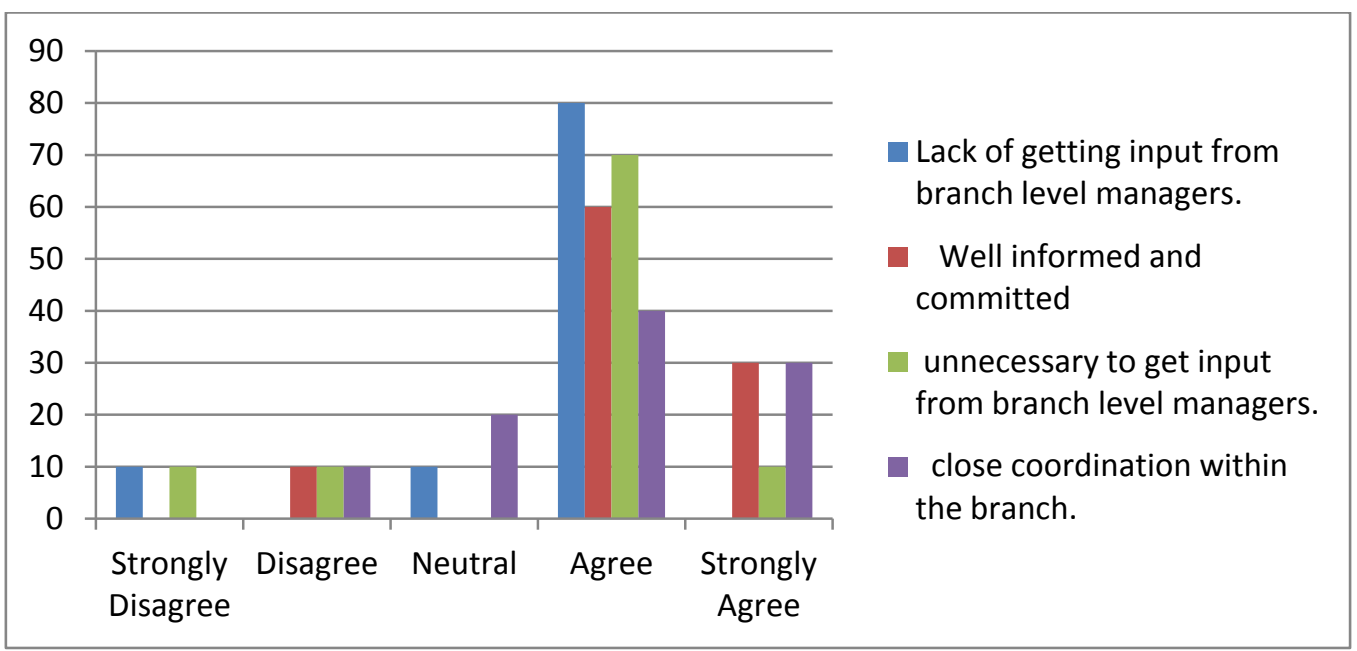

Fig 5

Approximately $80 \%$ of respondents agreed with the statement that certain decisions are failed because of not getting input from branch level managers, $10 \%$ disagreed and $10 \%$ remained neutral with the statement. $60 \%$ of respondents agreed, $30 \%$ strongly agreed and $10 \%$ remained neutral with the statement that branch level managers are well informed about decisions and are committed to implement the decisions. $70 \%$ of respondents agreed and $10 \%$ strongly agreed that top level managers do not get input from branch level managers because they have view point that there is no need of involving these managers in major decisions, $10 \%$ strongly disagreed and $10 \%$ disagreed with the statement. Approximately $70 \%$ of respondents have belief that there 
is close coordination in the bank (40\% of respondents agreed, $30 \%$ strongly agreed with the statement that there is closed coordination in the bank, $20 \%$ remained neutral and $10 \%$ disagreed with the statement.

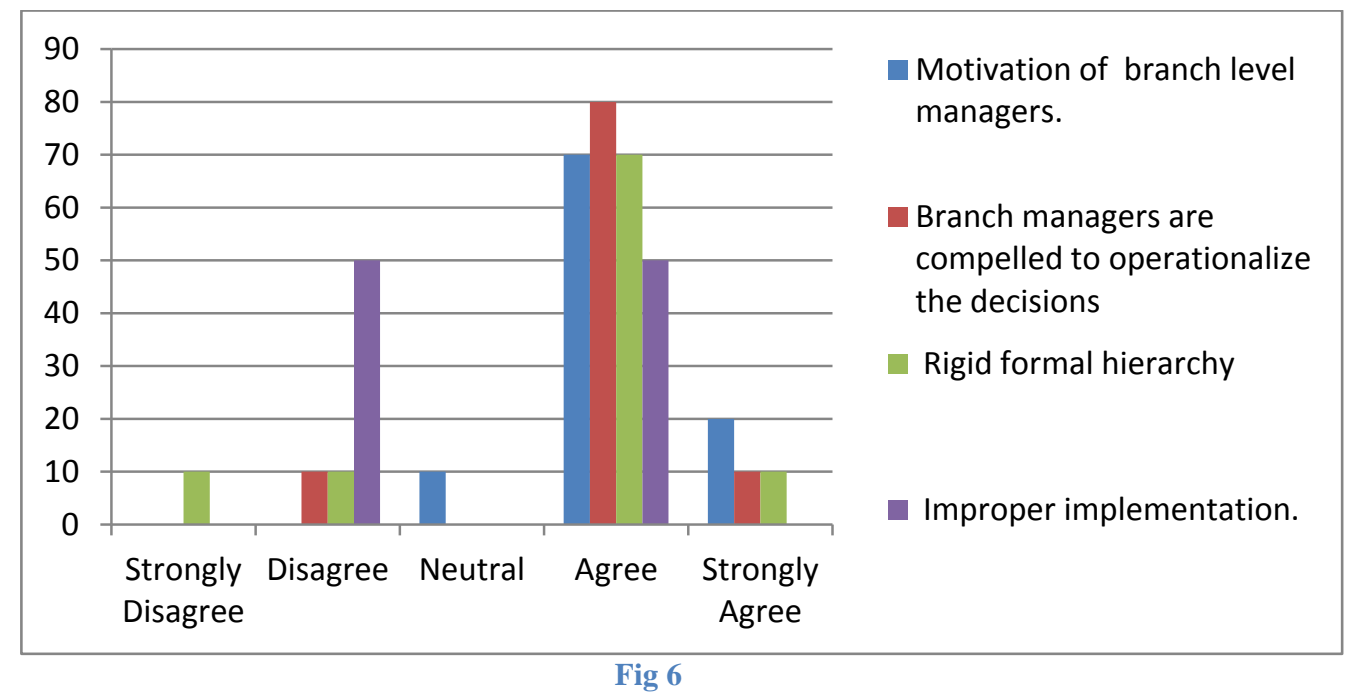

Approximately $90 \%$ of respondents have belief (70\% of respondents agreed and $20 \%$ strongly agreed) that top level management motivates branch level managers in order to get full commitment from branch level managers while implementing the decision $10 \%$ remained neutral with the statement. $80 \%$ of respondents agreed, $10 \%$ strongly agreed with the statement that branch level managers are compelled to implement the decisions even if it is obvious that decision has no benefit for the bank and $10 \%$ of respondents disagreed the statement. $70 \%$ of respondents agreed and $10 \%$ strongly agreed that due to rigid hierarchy and difficulty in access to upper level management there is difficulty in sharing views or providing suggestions to them,10\% strongly disagreed and $10 \%$ disagreed with the statement. An equal proportion of opinion about effectiveness of decisions (50\% of respondents agreed and $50 \%$ disagreed) is affected by improper implementation.

\section{Conclusions}

Top managers strongly favor and believe in rational analysis of strategic decisions. Top managers do not consider experience as enough criteria for taking strategic decisions. Top managers have strong view that, generally, problem is not identified properly that is again evident that managers' rationality is affected. This view supports Herbert A. Simon's Administrative model of decision making. Due to work burden of other managerial activities mostly managers have imperfect information for decisions. This situation again confirms the Administrative Model. It describes that managers actually take decisions under imperfect information 
about decision situation. Although satisficing in decision making had not been confirmed from the data and all respondents rejected situation of satisficing in their decisions. On the basis of data received through questionnaire and interviews, evidences suggest that the escalation of commitment exists in the organization. This aspect confirms the Administrative Model that also suggests that rationality of decision is affected by escalation of commitment. There is no clear evidence about existence of lobbing but implied meaning of responses suggests that lobbing does exist in organization. Due to unknown reasons, the responses that are provided by respondents neither rejected the existence of lobbing nor confirmed the existence of lobbing in the organization. Organization's communication is affected by rigid formal hierarchy having many layers resultantly there is communication gap between top and branches. Evidences also suggest that there is the problem of implementation of decisions as intended by top managers that may be the result of communication gap. There is strong opinion of managers in favor of intuition in decision making. They positively correlate intuition with quality of decision. But Administrative Model suggests that manager's rationality in decision making is affected by intuition because intuition is not based on rational thinking. There is strong contradiction between the opinion of top and branch level managers about getting the input from branch level managers for taking major decisions. Top level managers have opinion that they do get input from branches but branch managers have different opinion. It is evident from both data collected through questionnaire and interviews. Branch managers have strong belief that they can provide valuable information that can be used as input for taking major decisions. There is strong belief of branch managers that because of not getting input from branches, certain decisions are either failed or not provided the benefits as intended. Due to rigid hierarchy and formal communication it difficult for branch level managers to share their views or makes suggestions. There is no flexibility in decisions once decision is made branches have to implement it even it is obvious that decision is generating no benefit. 


\section{Reference:}

[1] Bei $\mathrm{Hu} \&$ Jiajun Gu, "An Empirical Study on the Influencing Factors of Effectiveness of Strategic Decision-Making and Its Relation with Performance Improvement: Evidence from China" Proceedings of IEEE IEEM, (2007) pp. 487-491

[2] Courtland Bovee et al," Management", New York, McGraw-Hill, (2000).

[3] Clifford F. Gray \& Erik W. Larson, "Project Management", New Delhi, Tata McGraw-Hill,(2006).

[4] Elbanna \& John child, "The Influence of Decision, Environment and Firm's Characteristics on Rationality of Strategic Decision Making, Journal of Management Studies", ( 2007), Vol:44:4, pp. 561-591.

[5] Fred R. David, "Strategic Management”, New York, Prentice Hal, (1998).

[6] Griffin, "Management", $5^{\text {th }}$ Edition, , U.S.A. Houghton Mifflin Company, (2006).

[7] Heinz Weihrich \& Harold Koontz, "Management", New York, McGrawHill, (2004)

[8] James W. Dean, Jr. \& Mark P. Sharfman, "The Relationship between Procedural Rationality and Political Behavior in Strategic Decision Making", Journal of Decision Sciences vol-24 No.6, pp.1069-1081, USA,

[9] Kathryn M. et al, "Management", New York, Irwin/McGraw-Hill, (1998).

[10] Luo Yong Tai, “DSS and Business Strategic Decision Making”, Proceeding of the $3^{\text {rd }}$ World Congress on Intelligent Control and Automation (June 22-July2, 2000), Hefei, P.R. China, .

[11] Prasanna Chandra, "Projects: Planning, Analysis, Selection, Financing, Implementation and Review", New Delhi, Tata McGrawHill,(2008). 